\title{
Failure Mode and Effects Analysis of a Process of Reflow Lead-Free Soldering
}

\author{
Pavel Mach and Aleš Duraj \\ Department of Electrotechnology, Faculty of Electrical Engineering, \\ Czech Technical University in Prague, \\ Prague, Czech Republic \\ mach@fel.cvut.cz,duraja@fel.cvut.cz
}

\begin{abstract}
There are many methods usable for production process optimization. The paper describes the use of Failure mode and effects analysis (FMEA of a process type) for the process of lead-free soldering improvement. The schedule of FMEA has been set. Then a flow chart of a process has been drawn and critical failures including their consequences for the final product have been described. Criteria for significance of failures characterization have been defined and have been used for evaluation of significance of failures. Diagnostic methods for critical failures have been proposed and corrective actions have been realized.
\end{abstract}

\section{INTRODUCTION}

Lead-free solders are materials, which substitute traditional tin-lead solders in mostly assembly companies. Therefore it is necessary to deal with a question of this new technology optimal implementation. With respect to the fact that the conversion of tin-lead soldering into the lead-free one is joined with some problems (e.g. with other types of soldering fluxes, with higher temperature of soldering, or with worst surface quality of the joints), it is necessary to introduce a detail analysis of problems joined with replacement of these two technologies. These analyzes are made using different ways. It seems that FMEA is a proper tool for such an analysis.

\section{THEORETICAL BACKGROUND}

Failure Mode and Effects Analysis (FMEA) was first developed by NASA in 1949 and later adopted by Ford Motor Company. Since this time this method has spread over the entire world. FMEA represents a very effective tool in measuring "control" of and process from design to manufacturing and service of a product. FMEA can be used for products and production processes as well. This tool required by QS9000 is a tool used to prevent problems from occurring [1]. FMEA is a tool that examines not only potential product or process failures and evaluates risk priorities, but it helps to determine remedial actions to avoid potential problems. FMEA is a systematic approach, which makes identification of potential failure modes in a product (caused by design) and manufacturing process (lead-free soldering in an assembly process, as for our case) possible. It identifies critical parts of a process, which needs special controls to prevent failure modes. FMEA is sometimes substituted with FMECA (Failure Mode and Effects Critically Analysis), which is more focused on analysis of critical parts in detail.

FMEA is focused on inspection and improvement of weak parts of a technological process, defines methods of failures diagnostics, shows how to do away with the failures, set deadlines for elimination of failures and defines responsibilities as well. FMEA shows also consequences of failures of components and technological processes on possible future failures of final products.

And at last, but not at least, a significant characteristics of FMEA is that it has to be carried out with maximum cost effectiveness [2].

Process of FMEA is a team-work. Brainstorming is an essential function of a FMEA process. The pooled know-how of the team members is directed to analyze potential failure modes as well as corrective measures.

Basic FMEA definition defines it as follows: FMEA is primarily a quality planning tool. It is useful in identification of critical product or process factors, 
in analysis of possible failures and problems cause by these factors, in establishing control mechanisms to avoid possible process failures and to optimize process operations to higher quality and reliability [3].

\section{FMEA METHODOLOGY}

FMEA is usually conducted in following steps:

Product or process is described.

Functions are defined.

Potential failure modes are identified.

Effects of failures are described.

Causes are determined.

Detection methods are chosen.

Possible risk is calculated.

Actions are taken.

Results are assessed.

When conducting the FMEA process, the first step is to map the system and to recognize all its steps. Then potential failures are brainstromed and problems caused by effects of these failures in every stage of the process are analyzed.

The content of FMEA depends on knowledge of experts. The structure of the team has to be made suitable to the tasks under solution. It is necessary to have a representation of every area of the production process if FMEA is directed to optimization of such a process.

The team of specialists is headed by a moderator. The duties of a moderator are as follows:

To have deep knowledge in FMEA.

To arrange preliminary work.

To control a brain-storming process of the FMEA team.

To implement improvement.

Composition of a FMEA team is shown in Figure 1.

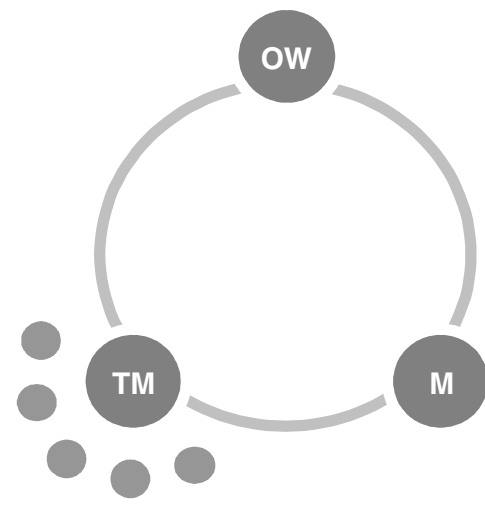

Figure 1 Composition of a FMEA team.
OW ... owner of FMEA, TM ... team

manager, $\mathrm{M}$... moderator

When the process is analyzed and described and possible failures are determined, it is necessary to define a metric for significance of failures evaluation. This metric is based on consequence of the failure on the production process. In most formal systems the consequences are evaluated by three criteria and associated risk indices:

Origin (S).

Significance $(\mathrm{O})$

Detectability (D).

Each index varies from 1 (lowest risk) to 10 (highest risk). The overall risk is called Risk Priority Number (RPN) and is calculated according the following formula:

\section{$R P N=S \times O \times D$}

The RPN (in the range 1 to $10^{3}$ ) is used to prioritize all possible 1 failures and to decide about actions leading to minimizing of occurrence of these failures together with improvement of methods for control and detection of failures.

The FMEA flo1w chart is shown in Figure 2

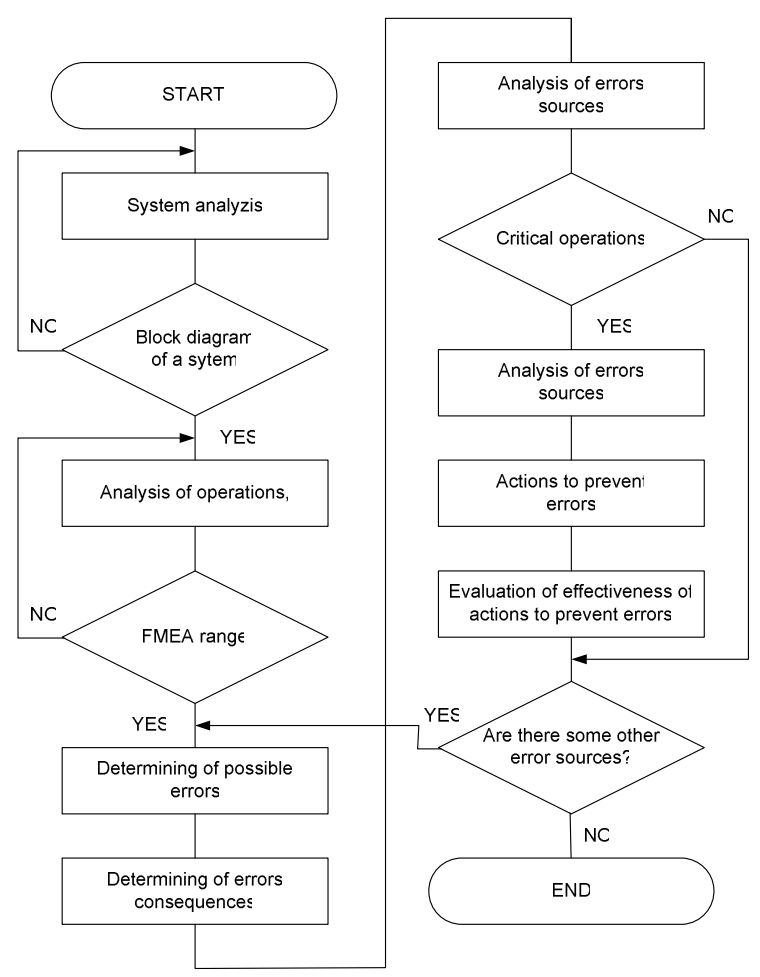

Figure 2.Process type FMEA flow chart 


\section{Process of Lead-Free Soldering}

\subsection{Steps of Lead-Free soldering}

The lead-free soldering process quality is influenced by following parameters:

Type of a lead-free soldering alloy, as the soldering temperature depends on the alloy type.

Material and surface finish of connected parts (leads of components and pads on PCB).

Type of flux used.

Type of atmosphere used (air or nitrogen).

Temperature profile of the soldering process.

Time of soldering.

Mechanical stability of a component vs. PCB during solidification of solder (no mechanical displacement of a component vs. PCB must occur during soldering).

Type of cooling of soldered joint during its solidification (unaffected cooling or forced cooling, e.g. using an air vessel).

Next parameters, which influence quality of soldering assembly process, are accuracy of solder paste printing or repeatability of the volume of printed solder paste. Printing accuracy influences position of mounted components, different volumes of the solder paste printed on pads, on which one component is mounted, can cause tombstoning of this component. As these parameters are not directly joined with the soldering process (they are joined with the solder paste printing process), they are not involved in FMEA analysis.

\subsection{Typical Failures in Lead-Free Soldering Process}

The presented parameters can cause following types of failures:

Too high soldering temperature can damage a mounted component or decrease its life time.

Improper surface finish (e.g. finish with low wettability) can cause worst mechanical and electrical properties of the joint.

Improper flux can cause worst mechanical and electrical properties of the joint.

Too high time of soldering can cause recrystalization of solder and decrease a soldered joint quality.

Mechanical displacement of a component vs. the PCB (caused e.g. by vibrations of a moving belt passing through a tunnel oven, whereat $\mathrm{PCBs}$ with components are situated) can cause a "cold" joint. This term is used for joints with faulty structure of the solder. Such the joint can be characterized as the joint with instability of electrical parameters, mainly the electrical resistance. The resistance fluctuates in wide limits randomly.

Voiding - the acceptable level for class 3 is $25 \%$ or less voiding in the volume of the solder (in accordance with the IPC standard). There is not proven correlation between voiding (in this maximum level for class 3) and joint quality. On the other hand, too high voiding level could influence mechanical properties of the joint. Therefore it is necessary to follow this parameter, too.

Improper nitrogen pressure (if the soldering process is carried out in the nitrogen atmosphere) can influence wettability of joined parts.

Rating of failure types is shown in Table 1.

Table 1. Rating of failure types

\begin{tabular}{|c|c|c|c|}
\hline Criterion & Levels & Frequency & Index \\
\hline \multirow[t]{5}{*}{ Origin } & improbable & 0 & 1 \\
\hline & $\begin{array}{ll}\text { very } & \text { low } \\
\text { probability } & \\
\end{array}$ & $<1 / 10000$ & 2 to 3 \\
\hline & low probability & $<1 / 2000$ & 4 to 6 \\
\hline & $\begin{array}{l}\text { middle } \\
\text { probability }\end{array}$ & $<1 / 100$ & 7 to 8 \\
\hline & high probability & $<1 / 2$ & 9 to 10 \\
\hline \multirow[t]{5}{*}{ Significance } & without effect & & 1 \\
\hline & insignificant & & 2 to 3 \\
\hline & $\begin{array}{l}\text { middle heavy } \\
\text { failure }\end{array}$ & & 4 to 6 \\
\hline & heavy failure & & 7 to 8 \\
\hline & $\begin{array}{ll}\text { very } & \text { heavy } \\
\text { failure } & \\
\end{array}$ & & 9 to 10 \\
\hline \multirow[t]{5}{*}{ Detectability } & high probability & & 1 \\
\hline & $\begin{array}{l}\text { middle } \\
\text { probability }\end{array}$ & & 2 to 5 \\
\hline & low probability & & 6 to 8 \\
\hline & $\begin{array}{ll}\text { very } & \text { low } \\
\text { probability } & \\
\end{array}$ & & 9 \\
\hline & improbable & & 10 \\
\hline
\end{tabular}

\section{Conclusions}

Failure Mode and Effect Analysis (FMEA) has been used for optimization of the soldering process used for SMT assembly. Soldering has been carried 
out using a lead free solder. Possible failures of the process and their consequences for quality of soldered joint have been analyzed, rating of failure types have been made, preventive actions have been proposed and actions realized have been described.

Understanding of FMEA improves understanding of a process and possible failures that can occur during its realization. A significant characteristic of this analysis is that it is used in early stage of design of a product and in early stage of its production. This way it makes possible to avoid failures in design and production "in advance".

Structure and conclusions of a FMEA record depends on quality of specialists, who prepare it. If other group of specialists is asked to elaborate a FMEA record on the same topic (the same production process), it is possible to assume, with high probability that the resulting FMEA record will differ in details. The principal failures and their elimination should be similar in both the records.

FMEA has been found a very effective tool for improvement of quality of a lead-free soldering process.

\section{ACKNOWLEDGMENTS}

The work has been carried out as a part of a project "Diagnostics of Materials", number MSM6840770021

\section{REFERENCES}

[1] Q-Base Engineering, QS 9000 Requirements, Failure Mode and Effect Analysis, pp. 1 to 3, 1998

[2] http://www.qbase.com.my/pdf/FMEA.pdf

[3] Stamatis, D. H.: Failure Mode and Effect Analyzis: FMEA from Theory to Execution. Quality Press, 2003

[4] Banerjee, N.: Utilization of FMEA concept in Software Lifecycle Management. Transactions on Information and Communication Technologies, Vol. 11, Wit press, pp. $219-230,1995$ 


\begin{tabular}{|c|c|c|c|c|c|c|c|c|c|c|c|c|}
\hline 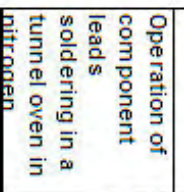 & 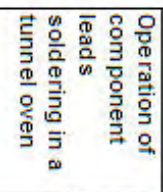 & 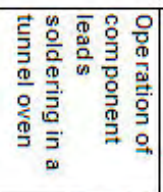 & 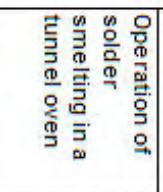 & 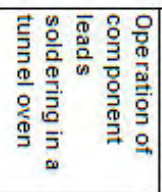 & 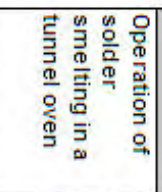 & $\frac{\vec{n}}{8}$ & 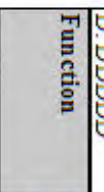 & 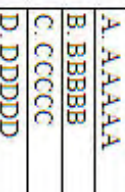 & 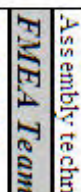 & 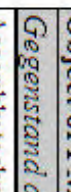 & 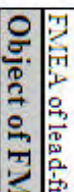 & 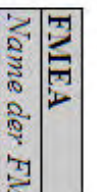 \\
\hline 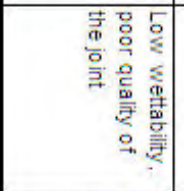 & 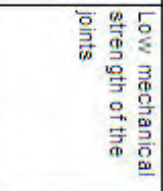 & 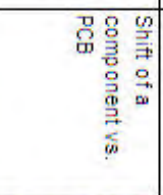 & 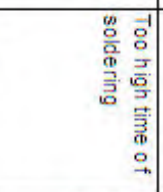 & 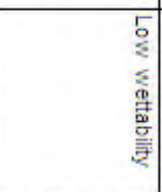 & 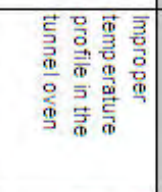 & 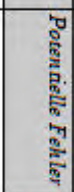 & 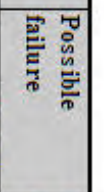 & & & & 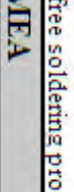 & \\
\hline 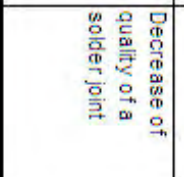 & 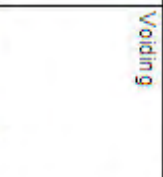 & 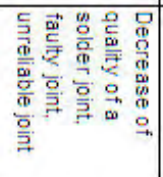 & 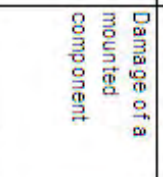 & 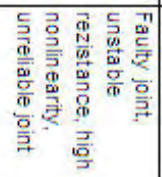 & 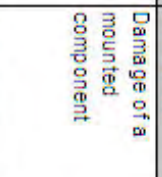 & 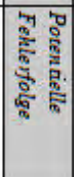 & 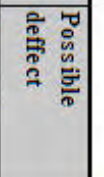 & & & & & \\
\hline 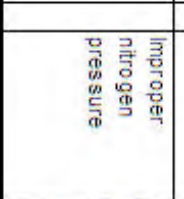 & 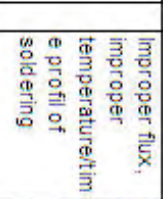 & 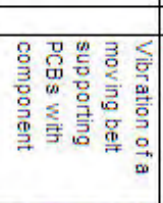 & 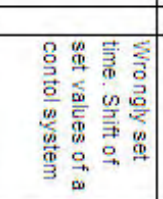 & 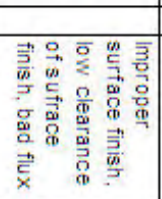 & 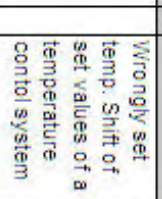 & $\begin{array}{l}5 \\
\frac{5}{2} \\
\frac{2}{2}\end{array}$ & 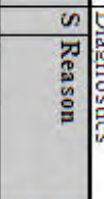 & \multirow{4}{*}{\multicolumn{2}{|c|}{ 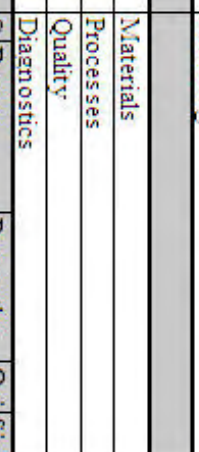 }} & \multirow{4}{*}{ 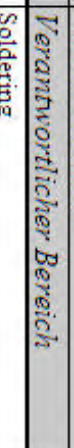 } & \multirow{4}{*}{ 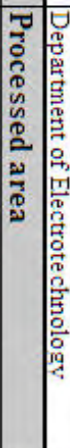 } & \multirow{4}{*}{ 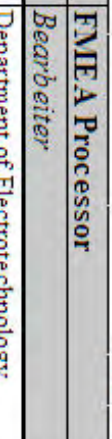 } \\
\hline 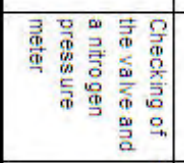 & 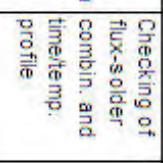 & 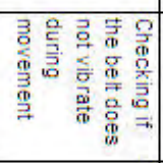 & 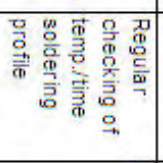 & 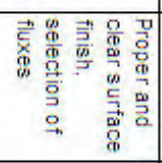 & 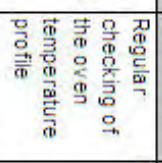 & 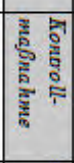 & 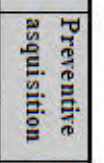 & & & & & \\
\hline & & & & & & $\backsim$ & 맾요. & & & & & \\
\hline & & & & $\infty$ & & 0 & $\sum_{5}^{5}$ & & & & & \\
\hline & 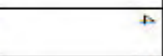 & $\omega$ & & क & & $\theta$ & 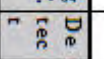 & & & \multirow{5}{*}{ 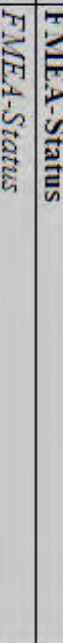 } & & \multirow{5}{*}{ 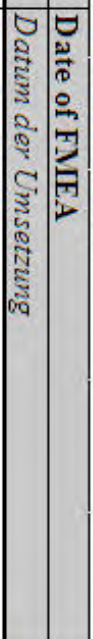 } \\
\hline & $\%$ & 战 & वे & 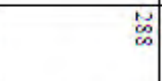 & $\overrightarrow{5}$ & 跑 & 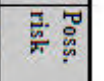 & & & & & \\
\hline 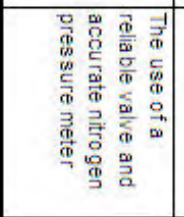 & 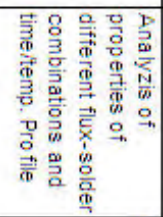 & 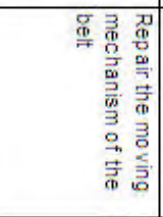 & 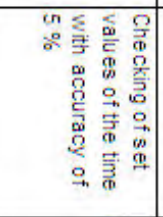 & 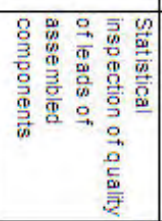 & 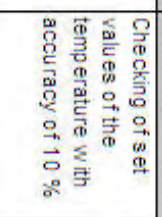 & 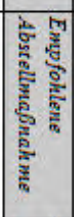 & 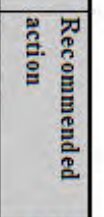 & & & & & \\
\hline 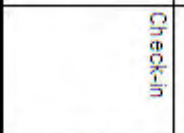 & $\begin{array}{l}\frac{9}{9} \\
\frac{0}{0} \\
\frac{0}{5} \\
\frac{1}{5}\end{array}$ & 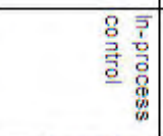 & 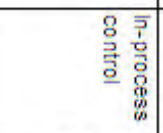 & $\begin{array}{l}0 \\
\frac{3}{0} \\
\frac{0}{1} \\
\frac{1}{5}\end{array}$ & 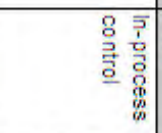 & 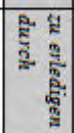 & 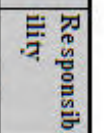 & & & & & \\
\hline 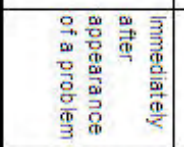 & 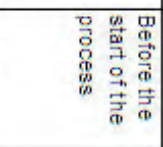 & 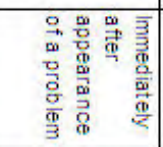 & 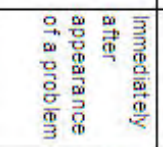 & 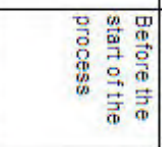 & 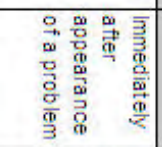 & & 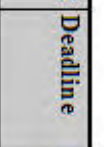 & & & & & \\
\hline 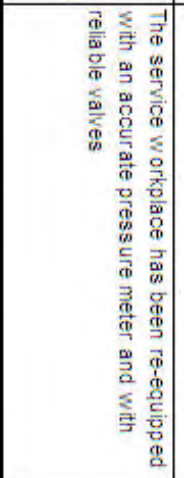 & 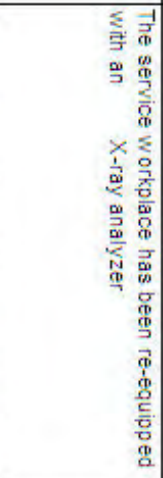 & 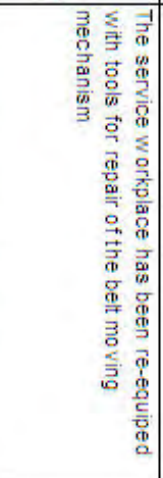 & 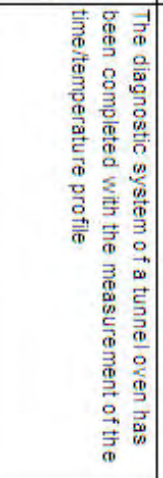 & 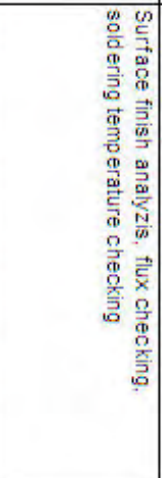 & 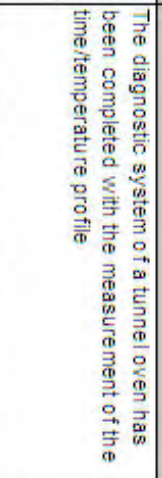 & 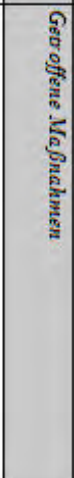 & 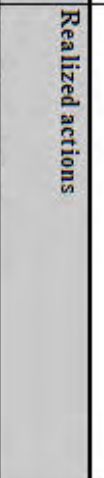 & & & 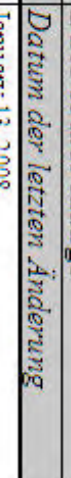 & 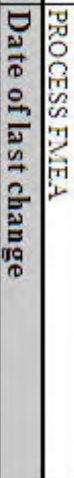 & 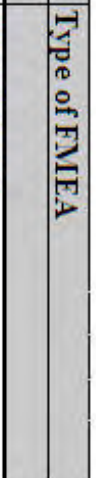 \\
\hline
\end{tabular}

